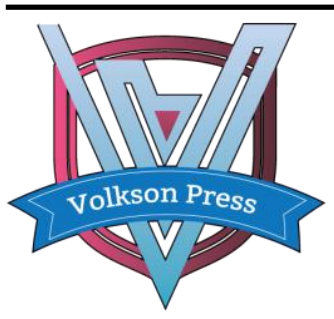

Contents List available at VOLKSON PRESS

Multidisciplinary Inclusive Education, Management

and Legal Services (MIEMLS)

Journal Homepage: https://topicsonsocialdevelop.com

DOI: $10.26480 /$ ismiemls.01.2018.29.31

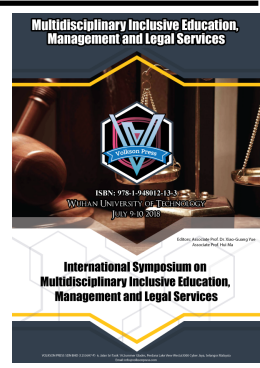

ISBN : 978-1-948012-13-3

\title{
RESEARCH ON THE POTENTIAL RISKS AND COUNTERMEASURES OF INTELLECTUAL PROPERTY RIGHTS IN EXTERNAL R\&D INSTITUTIONS
}

\author{
Meng Qixun ${ }^{1}$, Tian $\mathrm{Yu}^{2 *}$, Zhang Yinuo ${ }^{2}$ \\ ${ }^{1}$ Wuhan University of Technology Advanced Engineering and Technology Research Institute of Zhongshan City, Zhongshan Guangdong, China, \\ 528400 \\ ${ }^{2}$ College of Arts and Law, Wuhan University of Technology, Wuhan Hubei, China, 430070 \\ *Corresponding Author E-mail: 2281537513@qq.com
} This is an open access article distribyted under the Creative Commons Attribution License, which permits unrestricted use, distribution, and reproduction
in any medlum, provided the original work is properly cited.

\section{ARTICLE DETAILS}

Article History:

Received 26 June 2018

Accepted 2 July 2018

Available online 1 August 2018

\begin{abstract}
By using the methods of literature research, content analysis, comparative research and the related theories of economics, management, and law, this paper investigates incentive policies and development trends of external R\&D institutions and finds their formation mechanism from three aspects including the basic connotation, main content and the type of intellectual property risks. After introducing the influential factors and manifestations of intellectual property risks in external $R \& D$ institutions, this paper constructs the management system of them from five aspects: the management of intellectual property documents, resource management, acquisition strategy, application strategy and protection strategy of intellectual property.
\end{abstract}

\section{KEYWORDS}

External R\&D Institutions, Cooperative R\&D, Intellectual Property, Risk Management.

\section{INTRODUCTION}

Ulrich Beck, a German scholar, interprets the post-modern society as a "risk society-its main feature lies in the risk that human beings are faced with the threat of existence caused by the society". He also rethinks and criticizes the increasingly prominent social phenomenon of risk factors since the emergence of modernity from the angle of sociology in the "risk society: towards a new modernity" in 1986.

At present, the academic researches on intellectual property risks at home and abroad mainly include the legal risk of intellectual property, the risk of intellectual property in cooperative R\&D, the risk of intellectual property and the performance of the innovation alliance. In general, domestic and foreign academics have gained a lot of leading research achievements relatively in intellectual property risks, which mainly show two characteristics: First, the industrial demand is urgent, while the theoretical research is lagging behind. Second, there exist numerous scattered reports while the systematic research is insufficient. In view of this, the purpose of this paper is to clarify the formation mechanism and influential factors of intellectual property risks in external R\&D institutions, and to build a full-process risk prevention and control system of them from various dimensions such as document management, resource management and rights management, so as to establish a better effective linkage between the industrial chain, innovation chain and capital chain.

\section{THE INCENTIVE POLICIES FOR EXTERNAL R\&D INSTITUTIONS AND THEIR PRACTICES DEVELOPMENT TRENDS}

\subsection{The Incentive Policies for External R\&D institutions}

The state, provincial and municipal governments have issued a number of policies, laws and regulations related to promoting the development of new R\&D institutions (Table 1).

Table 1: National and local policies on intellectual property protection of new R\&D institutions

\begin{tabular}{|l|l|}
\hline Year & Related policies, laws and regulations \\
\hline 2017 & The 19th report of the Communist Party of China \\
2016 & The outline of the national innovation driven development strategy of China \\
2016 & Regulations on intellectual property management standard of higher learning and scientific research of China \\
2015 & $\begin{array}{l}\text { Implementation plan for deepening the reform of the scientific and technological system of China } \\
\text { The Outline of the National Intellectual Property Strategy of China }\end{array}$ \\
\hline
\end{tabular}



practice

The Shenzhen Municipal Government of Guangdong Province, as early as December 1996, cooperated with the Institute of Graduate school at Shenzhen Tsinghua University and began to develop new R\&D institutions [1]. By the end of 2017, the number of institutions in Guangdong had reached 219, and the total revenue of the institutions was expected to reach 101.5 billion RMB. Since 2017, 20 new R\&D institutions have been set up in Jiangsu Province, which have driven investment exceeding 2 billion RMB. And 172 million RMB provincial funds have been allocated for them. By the end of 2017, the number of new R\&D institutions in Jiangsu Province had reached more than 300, which had become an important force for innovation and development in service-supporting region. In 2017, 30 new provincial-level R\&D institutions had been established and developed in Fujian Province. In 2015, Henan province began to develop new R\&D institutions led by Zheng Luoxin. Now there are more than 40 new R\&D institutions in this province. Furthermore, there exist 48 new R\&D institutions in Anhui Province, involving multiple industrial fields.

In general, the development of external R\&D institutions has received strong support from state and provincial and municipal governments [2]. The central government has done the top-level design, and provincial and municipal governments also have introduced relevant supporting policies and gained advanced practical experience. The external R\&D institutions of Guangdong Province started early, and the policies and funding support for its cities were also the most complete. The quantity of resident in R\&D institutions there was also large. The political measures for external R\&D institutions in Jiangsu, Fujian, Anhui and other provinces and cities need to be further improved. The relevant government departments not only ought to support the development of them, but also strengthen their guidance in a right way.

\section{THE FORMATION MECHANISM OF INTELLECTUAL PROPERTY RISKS IN EXTERNAL R\&D INSTITUTIONS}

3.1 Basic Connotation of Intellectual Property Risks in External R\&D Institutions

Zhang Keying and other scholars pointed out that intellectual property risks refer to events and possibilities that have a negative impact on the current or potential rights and interests of owners of intellectual property rights. So the basic connotation of intellectual property risks in external R\&D institutions refers to the events and the possibility of negative impact on the current or potential rights and interests of owners of intellectual property rights, caused by the behavior of partners in external R\&D institutions. It is "a barrier to the successful acquisition of its own intellectual property rights and a stumbling block to the success of independent innovation [3]."

\subsection{The Main Content of Intellectual Property Risks in External} R\&D Institutions

The main contents of intellectual property risks in external R\&D institutions mainly include the following five aspects: First, the universality of intellectual property risks, which is inevitable for all R\&D activities. Second, the complexity of intellectual property risks, which is primaryly due to the nature of the parties to the cooperation, the needs of interests, and the complicated relationship. Thirdly, the coexistence of risks and interests of intellectual property, which is determined by its nature of the independent operation and self-financing. Fourth, the staged risks of intellectual property [4]. External R\&D institutions are facing greater intellectual property risks especially from producting to marketing. Meanwhile, the risks manifest differently in various stages. Fifth, the controllability of intellectual property risks and the risk of intellectual property rights will exhibit a certain regularity as well as general risks. They can be controlled by identifying and analyzing them.

\subsection{Classification of Intellectual Property Risks in External} R\&D Institutions

According to different causes, intellectual property risks can be divided into the risk of loss of intellectual property and the risk of intellectual property investment [5]. The former is due to the occupation or misappropriation of intellectual property rights by partners. The latter is due to the default of partners and the information asymmetry between the parties. According to different categories, intellectual property risk events can be divided into property rights risk, infringement risk, risk of loss of results and implementation of risk. According to different types, risk objects can be divided into copyright risk, patent risk, trademark risk, trade secret risk and so on.

\section{AFFECTING FACTORS AND MANIFESTATIONS OF INTELLECTUAL PROPERTY RISKS IN EXTERNAL R\&D INSTITUTIONS}

\subsection{Affecting Factors of Intellectual Property Risks in External R\&D Institutions}

Compared with traditional R\&D institutions, external R\&D institutions have carried out innovations in investment entities, technology research and development, management models, and operating mechanisms [6]. However, those differences in the diversification of investment entities and the knowledge structure and interests of all parties lead to the emergence of risk [7].

From the standpoint of external R\&D institutions, they mainly include malicious motives, lack of credit, incomplete contracts, lack of capacity and so on. From the perspective of the intellectual property's own characteristics, the affecting factors may also include intangibility, high costs, the transfer of media, the disclosure and destruction of rights etc.

\subsection{Manifestations of Intellectual Property Risks in External} R\&D Institutions

In the entire process of cooperative $\mathrm{R} \& \mathrm{D}$, the risks of intellectual property rights in external R\&D institutions are ubiquitous [8]. First, there are three main stages of distribution of intellectual property risk: partner selection, cooperation operation, and achievement distribution. Second, the risk of intellectual property rights of overseas $R \& D$ institutions is concentrated and reflected in various relations such as project development, R\&D, manufacturing outsourcing, sales and after-sales, protection, application evaluation, and human resource management etc.

\section{MEASURES FOR THE MANAGEMENT OF INTELLECTUAL PROPERTY RISKS OF EXTERNAL R\&D INSTITUTIONS}

In order to minimize the risk of intellectual property rights, the author proposes the following five aspects of the governance path for the intellectual property risk of external $R \& D$ institutions to improve the whole process risk prevention and control system of intellectual property rights.

\subsection{Intellectual Property Document Management Strategy}

Establish an intellectual property management of document and archive. In the process of cooperation, a clear contractual clause will be formulated to clearly explain the use of intellectual property within the scope of cooperation [9]. Strengthen and improve relevant materials and documents of intellectual property rights such as trademark registration and patent applications, as well as research and development records of R\&D activities, intellectual property review data, and confidentiality systems for scientific and technological achievements. Rationally design the system structure of software application, strengthen network management, and encrypt important data.

\subsection{Resource Management Strategy}

In terms of human resources management, employees' awareness of technological protection is strengthened through regular course training and signing of confidentiality agreements. In terms of financial resources management, rational allocation of institutional financial resources is needed. On the one hand, ensure that there are corresponding financial budgets and enforcement controls in all aspects of intellectual property applications, registration, registration, maintenance, evaluation, litigation, training, incentives, etc. On the other hand, ensure the reasonable use of intellectual property rights to achieve revenue. In the aspect of information resource management, we need pay close attention to intellectual property policies and laws and regulations and establish 
mechanisms for collecting, collating and tracking. Besides, we should integrate the resources of various government agencies, industry associations, and service organizations.

\subsection{Intellectual Property Acquisition Strategy}

In the selection of topics, we will select research-worthy and developing areas that have a bright future and certain technological basis. In the project link, a comprehensive search of intellectual property rights is conducted to prevent duplication of R\&D or technical barriers. In the implementation phase, attention must be paid to the protection of intellectual property rights and to the infringement of intellectual property rights of others. As a conclusion of the project, a reasonable plan shall be adopted to timely protect the R\&D results in the form of registration, registration, or trade secrets; the intellectual property acquired in the R\&D process shall be suspended according to the cooperation agreement, and the commercial secret shall be kept strictly confidential.

\subsection{Intellectual property application strategy}

Implement early-warning of intellectual property risks and manage the risks in the course of application. In the process of planning and promotion, the marketing plan, slogan, trademark, etc. involving new products shall be protected against the risk of infringement arising from the application for protection. Strictly abide by the contractual agreement and determine the ownership of R\&D results. A scientific and reasonable evaluation system shall be adopted to ensure the sharing of benefits during transfer licenses and make investment.

\subsection{Intellectual Property Protection Strategy}

Strengthen contract management. By means of contracts, disputes that may arise may be resolved in accordance with the agreement and the costs of risks may be reduced [10]. Establish a complete risk management process. Early warning of possible risks should be prioritized during the risk management process and lessons should be learned afterwards and finally the risk management process should be improved.

\section{CONCLUSION}

Based on the reference to intellectual property legal risk, intellectual property risk of cooperative research and development, and innovation alliance performance, this paper systematically reviews the policy texts of external R\&D institutions. In addition, the various types of intellectual property risks of foreign R\&D institutions are inspected in practice. On this basis, countermeasures and suggestions on the prevention and control of intellectual property risks are proposed, which provides a policy reference for the sound development of Chinese R\&D institutions overseas. This article fails to build an evaluation index model for the impact of intellectual property risk factors. There are still deficiencies in data collection and collation. These ought to be improved in future research.

\section{ACKNOWLEDGEMENT}

This paper is supported by the project "Research on the Potential Risks and Countermeasures of Intellectual Property Rights in External R\&D Institutions" (20182h0072) of Wuhan University of Technology Advanced Engineering and Technology Research Institute of Zhongshan City.

\section{REFERENCES}

[1] Lijun, W. 2017. Comparison and Enlightenment of Policies for Domestic New R\&D Institutions [J]. Hangzhou Science and Technology, (5), 31-34. (In Chinese)

[2] Huaizu, W., Guanghui, H. 2015. Research on Intellectual Property Risks of Industry-University-Research Cooperation Innovation [J]. Science and Technology Management Research, (3), 130-135. (In Chinese)

[3] Wenguang, Z., Ruihua, H. 2010. Research on the Early Warning Process of Intellectual Property Risk in Enterprise Independent Innovation [J]. Science of Science and Management of S.\&T., (4), 72. (In Chinese)

[4] Zeling, W., Jianxin, I. 2015. The Impact of Intellectual Property Risk on the Stability of R\&D Alliances: An Interpretation Based on Knowledge Characteristics [J]. Science of Science, (9), 1381-1388. (In Chinese)

[5] Bingquan, W. 2016. Analysis on the Connotation, Types and Characteristics of Intellectual Property Cooperation Risks in Collaborative Innovation Projects of Enterprises [J]. China International Finance \& Economics (Chinese/English), (23), 55-59. (In Chinese)

[6] Keying, Z., Yangdong, L., Wei, G. 2011. Research on the Influence of Intellectual Property Risk on Cooperative Behavior in Cooperative R\&D [J]. Management Review, (12), 76-83. (In Chinese)

[7] Shibin, S., Ruihua, H., Ruiqing, W. 2006. Research on Intellectual Property Risk Caused by Transfer Media in Collaborative Innovation [J]. Research and Development Management, (04), 72-76. (In Chinese)

[8] Passman, P. 2013. Understanding the Risks: Eight Elements of an Effective IP Protection Program [J]. Risk Management, October 1.

[9] Bin, L. 2013. Research on the Enterprise Intellectual Property Risk Management Standard in China [J]. China Standardization, (04), 39-43. (In Chinese)

[10] Li, Q., Yueping, D. 2011. The causes and prevention of intellectual property risk in cooperative innovation [J]. Reform and Strategy, 27 (10), 49-52. (In Chinese) 